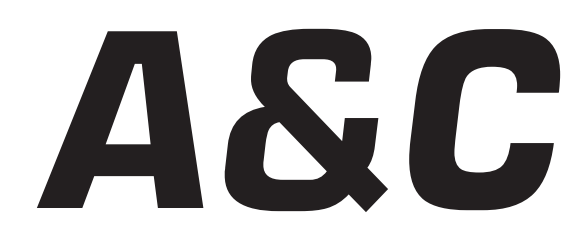

Revista de Direito Administrativo \& Constitucional

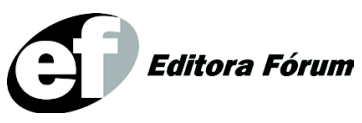

A\&C R. de Dir. Administrativo e Constitucional, Belo Horizonte, ano 6, n. 24, p. 1-246, abr.jun. 2006 


\section{A\&C REVISTA DE DIREITO ADMINISTRATIVO E CONSTITUCIONAL}

\section{IPDA}

Instituto Paranaense

de Direito Administrativo

Direção Geral

Romeu Felipe Bacellar Filho

Direção Editorial

Paulo Roberto Ferreira Motta

Direção Executiva

Emerson Gabardo

Conselho de Redação

Edgar Chiuratto Guimarães

Adriana da Costa Ricardo Schier

Célio Heitor Guimarães

Conselho Editorial

Adilson Abreu Dallari

Alice Gonzáles Borges

Carlos Ari Sundfeld

Carlos Ayres Britto

Carlos Delpiazzo

Cármen Lúcia Antunes Rocha

Celso Antônio Bandeira de Mello

Clèmerson Merlin Clève

Clóvis Beznos

Enrique Silva Cimma

Eros Roberto Grau

Fabrício Motta

Guilhermo Andrés Muñoz (in memoriam)

Jaime Rodríguez-Arana Muñoz

Jorge Luís Salomoni
José Carlos Abraão

José Eduardo Martins Cardoso

José Luís Said

José Mario Serrate Paz

Juan Pablo Cajarville Peruffo

Juarez Freitas

Julio Rodolfo Comadira

Luís Enrique Chase Plate

Lúcia Valle Figueiredo

Manoel de Oliveira Franco Sobrinho

(in memoriam)

Marçal Justen Filho

Marcelo Figueiredo

Márcio Cammarosano

Maria Cristina Cesar de Oliveira
Nelson Figueiredo

Odilon Borges Junior

Pascual Caiella

Paulo Eduardo Garrido Modesto

Paulo Henrique Blasi

Paulo Neves de Carvalho (in memoriam)

Paulo Ricardo Schier

Pedro Paulo de Almeida Dutra

Regina Maria Macedo Nery Ferrari

Rogério Gesta Leal

Rolando Pantoja Bauzá

Sérgio Ferraz

Valmir Pontes Filho

Yara Stropa

Weida Zancaner

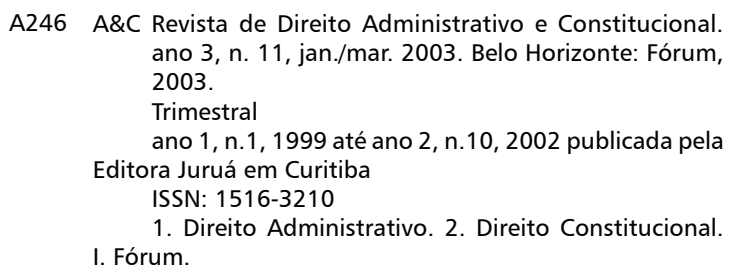

A246 A\&C Revista de Direito Administrativo e Constitucional. ano 3, n. 11, jan./mar. 2003. Belo Horizonte: Fórum, 2003.

Trimestral

ano 1, n.1, 1999 até ano 2, n.10, 2002 publicada pela Editora Juruá em Curitiba

ISSN: 1516-3210

1. Direito Administrativo. 2. Direito Constitucional. I. Fórum.

CDD: 342 CDU: 33.342

(c) Editora Fórum Ltda. 2006

Todos os direitos reservados. É proibida a reprodução total ou parcial, de qualquer forma ou por qualquer meio eletrônico ou mecânico, inclusive através de processos xerográficos, de fotocópias ou de gravação, sem permissão por escrito do possuidor dos direitos de cópias (Lei nº 9.610, de 19.02.1998).

\section{Editora Fórum Ltda}

Av. Afonso Pena, 2770 - 15\%16ªndar - Funcionários

CEP 30130-007 - Belo Horizonte/MG - Brasil

Tel.: 08007043737

Internet: www.editoraforum.com.br

e-mail: editoraforum@editoraforum.com.br
Editor responsável: Luís Cláudio Rodrigues Ferreira Projeto gráfico e diagramação: Luis Alberto Pimenta Revisora: Olga M. A. Sousa

Pesquisa jurídica: Fátima Ribeiro - OAB/MG 74868

Bibliotecária: Alessandra Rodrigues da Silva CRB 2778/MG 6a Região

Os conceitos e opiniões expressas nos trabalhos assinados são de responsabilidade exclusiva de seus autores.

Impressa no Brasil / Printed in Brazil

Distribuída em todo Território Nacional 


\title{
Constituição e democracia: reflexões sobre permanência e mudança da decisão constitucional
}

\author{
Gustavo Ferreira Santos \\ Professor de "Direito Constitucional", nos Bacharelados em Direito da UFPE e da UNICAP e de \\ "Teoria dos Direitos Fundamentais" no Mestrado e Doutorado em Direito da UFPE. Procurador \\ Judicial do Município do Recife
}

Palavras-chave: Constituição. Constitucionalismo. Estado de Direito. Estado Constitucional. Democracia.

Apesar do papel de destaque que a Constituição conhece nos nossos tempos, ainda é possível localizar na doutrina críticas ao seu papel e, especialmente, à legitimidade da rigidez e das chamadas cláusulas pétreas. Nesse contexto, as maiores críticas fundam-se em argumentos valorizadores da democracia que, à medida que determinadas matérias são consideradas de alteração proibida ou dificultada, vê minguar o conjunto de matérias colocadas a debate.

Neste trabalho, refletimos sobre alguns aspectos do problema da conceituação e do papel da Constituição no contexto do chamado Estado constitucional. Em especial, enfatizamos a tensão verificada na relação entre as necessidades permanência e mudança, justificáveis na própria Constituição.

O termo constituição pode ser usado nos mais diversos contextos. Falamos em constituição física de uma pessoa para expressar sua estrutura. Mencionamos constituição de uma empresa quando queremos tratar de seu ato fundador. Mesmo especificando que o uso que se faz é eminentemente jurídico, restam, ainda, diversos significados atribuíveis ao termo. Portanto, necessário se faz analisar as acepções que a doutrina admite. Em especial, estudos deste tipo, que cuidam de elementos da herança do constitucionalismo, pedem que sejam esclarecidos os limites do uso do conceito.

A \& C R. de Dir. Administrativo e Constitucional, Belo Horizonte, ano 6, n. 24, p. 163-174, abr./jun. 2006 
Em Canotilho encontramos uma passagem que expressa de forma condensada três perspectivas a partir das quais o conceito de Constituição pode ser apreendido:

Todos os países (quaisquer grupos sociais organizados) têm uma constituição; mas nem todos os países têm um documento escrito chamado constituição; e nem todos os que têm um documento constitucional possuem uma constituição filtrada pela idéia de constitucionalismo.

Nessa fórmula estão contidos três pontos de vista sobre a constituição. Um primeiro conceito diz respeito à forma de ser de uma sociedade política, sendo, portanto, exclusivamente material. Um segundo conceito trata da constituição-documento, ou seja, toma a constituição como forma. Enquanto um terceiro sentido de Constituição agrega elementos formais e elementos materiais.

No primeiro sentido, todos os países têm constituição, independentemente do lugar e do tempo. Quando, em sua "Política", Aristóteles falava em constituições das cidades-estado gregas, era com um significado próximo dessa acepção que ele tomava o termo: a forma de funcionamento uma associação política, estejam as instituições reduzidas ou não a documentos.

Assim, independentemente de ser ela reduzida à palavra escrita, ela pode ser apreendida na observação das relações concretas desenvolvidas pelas pessoas e grupos que exercem ou disputam o poder político. A crítica à constituição-norma, geralmente fundada em conceitos sociológicos, parte desse ponto de vista de Constituição.

Lassale, por exemplo, quando diz que a Constituição é a soma dos fatores reais de poder, tem em mente a correlação de forças entre as classes sociais, sendo a Constituição mero reflexo de tais relações. Charles Beard, quando, nos Estados Unidos, fez uma análise das determinantes econômicas da Constituição do país pensava na Constituição como o acordo dos diversos interesses que dominavam a economia.

O segundo sentido de Constituição diz respeito à Constituição escrita. Segundo o já citado ensaio de Lassale, não é a constituição que é um fenômeno típico da modernidade, mas sim a constituição escrita. Nessa conhecida afirmação, a constituição está claramente sendo tomada no segundo dos sentidos aqui comentados, ou seja, como o documento no qual são identificadas as instituições de um Estado. Porém, essa constituição escrita passa a ser instrumento essencial para os Estados que decorrem das revoluções burguesas.

A \& C R. de Dir. Administrativo e Constitucional, Belo Horizonte, ano 6, n. 24, p. 163-174, abr.jun. 2006 
É possível que um país tenha a Constituição escrita mesmo que essa Constituição não exerça concretamente as funções de contenção do poder, funções típicas de sistemas influenciados pelo constitucionalismo. Países como a China ${ }^{1}$ ou países do oriente médio, apesar de inseridos em outra tradição jurídica, têm documentos constitucionais. ${ }^{2}$

O último dos sentidos remete a idéia de constituição a uma dimensão material. Ela não é a pura forma de existir de um Estado, nem é qualquer documento que assuma o nome de constituição. Para ser assim considerada, deve trazer uma evidente carga hereditária do constitucionalismo, contendo o poder e garantindo autonomia aos membros da sociedade.

Como sabemos, o art. 16 da Declaração de Direitos do Homem e do Cidadão da Revolução Francesa diz não ter uma constituição o país que não divide poderes e nem declara direitos. Essa é a imagem da constituição segundo o constitucionalismo liberal: um instrumento de contenção do poder. O dispositivo, também, delimita um campo material que estaria na essência da Constituição, seja para liberais que vêem a constituição como instrumento de limite do Estado, seja para outros pensadores que incluem outras tantas matérias na sua visão de Constituição.

É este conceito que habita o imaginário dos juristas e que aparece na política. A determinação racional dos princípios que regem o destino político da comunidade, consagrando direitos humanos, atribuindo funções a determinados órgãos e criando controles para o poder é que pode ser destacado como característica da Constituição que se vem construindo no ocidente desde os fins do século XVIII. ${ }^{3}$

O tamanho do texto refletirá evidentemente a específica situação da sociedade que adota um novo parâmetro constitucional. O povo dos Estados Unidos da América, no nascimento da Constituição, não necessitava e não desejava ter um amplo texto. Os principais problemas que queriam desde já equacionar giravam em torno do pacto federativo, núcleo do texto originário. Optaram por construir um texto com abertura suficiente para o futuro. No Brasil, em 1987 e 1988, pairava um clima de

\footnotetext{
Cf. IMPRENSA Oficial. Macau. Disponível em: <http://www.imprensa.macau.gov.mo/bo/i/1999/ constituicao/index.asp $>$.

2 "As monarquias tradicionais da Ásia e do Pacífico (Arábia Saudita, Nepal, Brunei, Tonga, até há alguns anos Etiópia e Irão) caracterizam-se por: a) ausência de uma constituição formal; b) subsistência do princípio da legitimidade monárquica, indissociável de uma base religiosa; c) regime de união do Estado com a comunidade religiosa; d) domínio pleno pelo monarca de todo o processo político, com um ou outro mecanismo de autolimitação; d) autoritarismo conservador" (MIRANDA, Jorge. Manual de Direito Constitucional. Coimbra: Coimbra Ed., [198-]. t. 1, p. 222).

3 HELLER, 1968, p. 321.
}

A \& C R. de Dir. Administrativo e Constitucional, Belo Horizonte, ano 6, n. 24, p. 163-174, abr./jun. 2006 
desconfiança em relação à lei e ao Executivo, muitos agentes consideravam fundamental garantir suas posições jurídicas já no texto da Constituição. Os resultados das duas experiências, como se sabe, são totalmente diferentes, com um texto mais enxuto nos Estados Unidos, repleto de princípios, e um texto mais detalhista, no Brasil, com um excessivo número de regras.

Porém, independentemente da opção por mais ou por menos Constituição, mesmo destacando que o conteúdo herdado do constitucionalismo é essencial, é necessário reconhecer que, na prática das instituições, o conceito formal ${ }^{4}$ de Constituição adquire papel central. Não importa, para efeito de observância das ordens contidas na Constituição, se a matéria objeto da norma está ou não está naquilo que os autores entendem ser materialmente constitucional. O que importa é que no exercício do Poder Constituinte tenha sido incluída aquela norma naquilo que será para a sociedade sua Constituição.

As prefaladas características da Constituição que decorrem do constitucionalismo não escondem a diversidade que o ideal constitucionalista contém. Mais do que em "constitucionalismo", é possível falar em "constitucionalismos", ${ }^{5}$ tanto sob o ponto de vista histórico-geográfico, dada a variedade de concepções de Constituição encontráveis na Grãbretanha, nos Estados Unidos e na França, cada qual refletindo uma peculiar experiência histórica, como sob um ponto de vista históricoideológico, haja vista serem passíveis de inclusão no conceito de constitucionalismo as concepções dos defensores, por exemplo, do Estado Social ou de um novo Estado Ecológico.

A experiência britânica, por exemplo, é bem peculiar, de tal forma que, apesar da coincidência de certos princípios e valores em relação à Europa continental, manteve a Grã-bretanha sem uma Constituição formal. Não que a Constituição seja não-escrita. Essa classificação é deveras reducionista, à medida que desconsidera o conjunto de documentos, consolidados em momentos históricos distintos, e que fazem parte daquilo que o britânico chama de Constituição. Seria mais adequado falar que a

\footnotetext{
4 Constituição formal como "certo documento solene, um conjunto de normas jurídicas que pode ser modificado apenas com observância de prescrições especiais cujo propósito é tornar mais difícil a modificação dessas normas" (KELSEN, 1992, p. 130).

5 "Em termos rigorisos, não há um constitucionalismo mas vários constitucionalismos (o constitucionalismo inglês, o constitucionalismo americano, o constitucionalismo francês). Será preferível dizer que existem diversos movimentos constitucionais com corações nacionais mas também com alguns momentos de aproximação entre si, fornecendo uma complexa tessitura histórico-social" (CANOTILHO, 1998, p. 45).
} 
Inglaterra tem uma Constituição evolutiva. ${ }^{6}$

Ninguém desconhece as lutas políticas pelo controle do poder que marcam a história inglesa. Inclusive, muitas conquistas desse longo processo evolutivo foram influenciar os constitucionalismos norte-americano e francês. Documentos como a Magna Carta de João Sem Terra, a Petição de Direitos e a Carta de Direitos podem ser tomadas como precedentes para as declarações de direitos das constituições modernas. ${ }^{7} \mathrm{O}$ papel do Parlamento como instrumento de garantia de liberdades também pode ser apontado como uma peculiaridade desse sistema. ${ }^{8}$

Os norte-americanos receberam uma nítida influência do novo pensamento político europeu à época da colônia. Construíram, com sua independência, um Estado no qual efetivamente há diferença entre norma constitucional e norma infraconstitucional. Já que nas colônias o Parlamento não era tão bem visto como na matriz, os norte-americanos fixaram controles recíprocos para os órgãos que expressam a soberania. ${ }^{9}$

Na França, aparece no centro da experiência de constitucionalismo o princípio da separação de poderes, ${ }^{10}$ que conhece uma leitura bem própria que resultará, em nossos dias, na dualidade de jurisdição e na ausência de jurisdição constitucional. Os franceses, receosos de que a obra da revolução fosse renegada, cuidaram para tornar efetiva a decisão do Estado-administração.

\section{II}

O status da Constituição na vida política foi expressivamente alterado com a evolução das primeiras formas liberais de Estado aos nossos dias. De início, o papel da lei era de evidente destaque. Esse papel decorria das características que marcavam o chamado Estado de Direito.

A expressão "Estado de Direito" remete a um amplo conjunto de significados e de experiências. ${ }^{11}$ Nele está resumida uma necessidade de compatibilização entre liberdade e ordem, pois, segundo Reinhold Zippelius, ele "procura um compromisso entre a necessidade de um poder do Estado homogêneo e suficientemente forte para garantir a paz jurídica

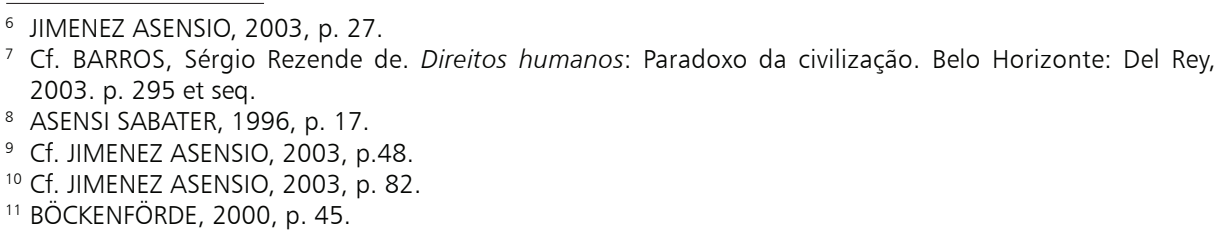

A \& C R. de Dir. Administrativo e Constitucional, Belo Horizonte, ano 6, n. 24, p. 163-174, abr.jun. 2006 
e a necessidade de prevenir um abuso do poder estatal e de estabelecer limites a uma expansão totalitária do poder do Estado, assegurando na maior medida possível os direitos individuais". ${ }^{12}$

O Estado de Direito não é apenas o Estado segundo a lei. Do surgimento dessa noção aos dias atuais ele deve ser entendido como o Estado que se guia por princípios da razão. Canotilho afirma que ele deve ser tomado como um esquema organizatório limitado pelo Direito. ${ }^{13}$ Com essa noção, não há Estado fora do Direito.

Nesse caminho, Canotilho assenta que só será um Estado considerado Estado de Direito quando: (1) está sujeito ao direito ("o Estado, os governantes, as autoridades, obedecem às leis, não estão colocados sobre as leis, mesmo que elas tenham sido criadas ou produzidas pelos órgãos do poder"); (2) atua através do direito ("só quem esteja habilitado, só quem tenha uma competência previamente definida por regras jurídicas, está apto, num qualquer Estado de Direito, a desempenhar funções com o selo de autoridade pública”); (3) positiva normas jurídicas informadas pela idéia de direito ("O Estado de direito é informado e conformado por princípios radicados na consciência jurídica geral e dotados de valor ou bondade intrínsecos"). ${ }^{14}$

O "Estado de não direito", antítese do Estado de Direito, poderia ser assim caracterizado: "(1) é um Estado que decreta leis arbitrárias, cruéis e desumanas; (2) é um Estado em que o direito se identifica com a 'razão de Estado' imposta e iluminada por 'chefes'; (3) é um Estado pautado por radical injustiça e desigualdade na aplicação do direito". ${ }^{15}$

A proeminência da lei no pensamento liberal decorre do fato de que os Parlamentos surgiram, à época do absolutismo, como instrumentos de afirmação da liberdade perante do poder. No conceito de Estado de Direito novecentista não está presente o medo do Parlamento, mas sim o do arbítrio da Administração. O próprio conceito de Estado de Direito traz em si a idéia de que só a lei é o instrumento adequado para a restrição de direitos individuais.

Veja-se, a esse respeito, a imagem que Otto Mayer tinha de Rechtsstaat, que se marcava pela (i) supremacia da lei sobre a Administração; (ii) na subordinação à lei, e somente à lei, dos direitos do cidadão, não

\footnotetext{
12 Teoria Geral do Estado, p. 384.

${ }^{13}$ CANOTILHO, 1999, p. 15.

${ }^{14}$ CANOTILHO, 1999, p. 49

${ }^{15}$ CANOTILHO, 1999, p. 12.
}

A \& C R. de Dir. Administrativo e Constitucional, Belo Horizonte, ano 6, n. 24, p. 163-174, abr.jun. 2006 
podendo poderes autônomos incidir sobre tais direitos; (iii) a presença de juízes independentes com competência exclusiva para aplicar a lei, e somente a lei, nas controvérsias surgidas entre os cidadãos e entre eles e a Administração. ${ }^{16}$

A posição de destaque no cotidiano da Jurisdição Constitucional hoje observado quanto aos direitos fundamentais é de fácil explicação. Trata-se de um evidente reflexo do câmbio do próprio conceito de Constituição, que caminhou de uma posição privilegiadora de normas organizacionais para uma ênfase nas normas protetivas de indivíduos e grupos em face do poder.

Reflete, ainda, a crise do estado legislativo e do próprio conceito de lei. A coerência do ordenamento, criado sob os auspícios de interesses de um grupo, que caracterizou o Estado burguês, não comparece no atual Estado constitucional. A caótica inclusão de temas em leis, nos diversos acordos momentâneos de interesses que se verifica na atividade parlamentar da atual sociedade pluralista vai encontrar nos princípios constitucionais um mínimo conteúdo referencial. Na Constituição encontram-se termos de um acordo mais amplo, capaz de nortear os embates cotidianos de interesses. A lei cede espaço à Constituição como elemento mediador. ${ }^{17} \mathrm{O}$ Estado Constitucional representaria, assim, um plus em relação ao Estado de Direito.

Nesse contexto, interpretação constitucional substitui, em muitos aspectos, o debate político. A decisão que sairia do embate entre propostas melhores ou piores cede lugar muitas vezes à adoção de medidas segundo a constitucionalidade. As próprias forças políticas incorporam o argumento da constitucionalidade aos seus discursos. É mais forte, pela autoridade que contém, do que argumentos sobre virtudes práticas das medidas propostas.

Porém, a revalorização do papel da lei é também uma revalorização da democracia.

Muitas críticas dirigidas ao legislador, questionando a sua legitimidade, geralmente deflagradas em razão de problemas cotidianos, tais como corrupção no Estado ou acordos espúrios, atingiriam, se a ela dirigida, a própria assembléia que construiu a Constituição. Muitas dessas críticas, na verdade, tratam de um constituinte mítico, imaculado, iluminado e distante dos conchavos que marcam o dia a dia da política, ou

${ }^{16}$ MAYER apud ZAGREBELSKY, 1999, p. 23.

${ }^{17}$ Cf. a respeito ZAGREBELSKY, 1999, p. 40.

A \& C R. de Dir. Administrativo e Constitucional, Belo Horizonte, ano 6, n. 24, p. 163-174, abr./jun. 2006 
seja, uma entidade inexistente.

É evidente que os instrumentos complexos das democracias atuais são imperfeitos. Pior, ainda, é a prática que se verifica na execução de tais instrumentos. Porém, esses problemas não podem justificar o desprezo pela decisão democrática. É evidente que, apesar dos problemas, a figura da representação aporta uma legitimidade ao representante que não encontramos no indivíduo isolado sentado numa cadeira na Universidade. Em nada o professor de direito constitucional será mais legítimo que o parlamentar. Adiante, discutiremos com mais vagar esse problema da legitimação democrática dos detentores do poder.

\section{III}

A Constituição, em sua supremacia, coloca o problema da relação entre atualização e permanência das decisões políticas. Ao instituir-se como comunidade, um povo escolhe a forma e o conteúdo de suas instituições. Exerce o poder de dizer como o Estado e a sociedade se organizarão. Ao mesmo tempo, em razão do estabelecimento da rigidez constitucional, retira da atividade política cotidiana o poder de alterar tais decisões. ${ }^{18}$

Identifica-se, nessa seara, o que Holmes chamou de "paradoxo democrático", ou seja, como pode uma geração que suplanta a obra constitucional da geração anterior impor às gerações futuras a sua obra constitucional ${ }^{19}$

Como se sabe, não há Constituições imutáveis. Uma Constituição que se pretendesse imutável seria indubitavelmente uma Constituição breve. As alterações nas relações concretas na sociedade por ela regulada levariam à sua implosão, diante da impossibildade de adaptação do texto à vida. Com Jorge Miranda podemos dizer que a "modificação das Constituições é um fenômeno inelutável da vida jurídica, imposta pela tensão com a realidade constitucional e pela necessidade de efetividade que as tem de marcar". ${ }^{20}$

As Constituições, nesse processo de atualização, sofrem alterações tanto por processos formais, como a revisão ou a emenda, como por

\footnotetext{
${ }^{18}$ Garzón Veldés chama de "coto vedado" a área não passível de discussão pela atividade parlamentar (1989, p. 157)

19 HOLMES, 1988, p. 175
}

A \& C R. de Dir. Administrativo e Constitucional, Belo Horizonte, ano 6, n. 24, p. 163-174, abr.jun. 2006 
processos informais, como na chamada mutação constitucional. Num ou noutro momento, manifesta-se. Num ou noutro, o que se busca é manter a norma constitucional como parâmetro para a solução dos problemas da vida.

Ordinariamente, as Constituições regulam os processos a serem observados para a sua própria alteração. Constituições rígidas trazem formas especiais de processo legislativo para que algo em seu texto seja mudado. ${ }^{21}$ São momentos, atores ou quoruns específicos, acrescendo, portanto, ao princípio da maioria, exigências que não são exigidas para as decisões políticas diárias.

Quanto mais Constituição tiver um país, ou melhor, quanto maior for o número de matérias incluídas na Constituição formal, maior será o conjunto de temas submetidos a um processo político mais complexo ou, o que é pior, à imutabilidade. ${ }^{22}$

Essa supremacia/rigidez tem suscitado objeções, fundadas na afirmação da democracia. Questionam tais posicionamentos a necessidade de retirar da sociedade o poder de decidir seus rumos frente aos problemas que a vida apresenta. $\mathrm{O}$ entrincheiramento de determinadas decisões tem evidente tensão com o elemento democrático do Estado.

A Constituição, ao dificultar ou vetar a alteração de alguns de seus dispositivos, estaria conduzindo um paternalismo, decorrente de uma desconfiança em relação às gerações futuras. Seria um auto-reconhecimento de lucidez, concomitante a uma proteção de suas iluminadas decisões.

No caso brasileiro há um discurso comum de condenação às diversas alterações impingidas ao texto constitucional. É evidente que alterar com freqüência abala a força normativa que se espera de uma Constituição. No entanto, essa constatação não pode ser o único móvel para a permanência do texto. A Constituição tem que se mostrar apta a regular os problemas que a sociedade enfrenta. Se seus dispositivos não mais correspondem às expectativas dos principais atores políticos, a mudança apresenta-se como

\footnotetext{
${ }^{20}$ MIRANDA, Jorge. Manual de Direito Constitucional. Coimbra: Coimbra Ed., [198-]. t. 1, p. 129.

${ }^{21}$ Laporta considera como as formas mais comuns de proteção constitucional contra alterações são o quorum qualificado (que é diferente do exigido para as leis), as "cláusulas de esfriamento" (como a necessidade de mais de um turno de votação) e o plebiscito (2001, p. 466).

22 "Toda a discussão americana tradicional entre constitucionalistas e democráticos roda à volta deste ponto, como bem o sabemos. O problema consiste em saber até que ponto é que a excessiva constitucionalização não se traduz em prejuízo do princípio democrático. Constitucionalizar é colocar fora do comércio político, que o mesmo é dizer: fora do alcance da vontade da maioria daquilo que é constitucionalizado" (MOREIRA, 2001, p. 273).
} 
uma saída recomendável.

Da mesma forma, não podemos deixar de reconhecer que, quanto maior for o plexo de matérias e quanto mais profunda em detalhes tiver sido a regulação, maior será também a possibilidade de que uma necessidade de mudança de política leve a uma necessidade de intervenção no texto da Constituição. Não se pode esperar de um governo democraticamente eleito, muitas vezes com uma plataforma reformista, que se acomode na função de mero executor das decisões tomadas em 1987 e 1988.

Ninguém pode desconhecer as profundas mudanças que atingiram o mundo no período entre a elaboração de nossa atual Constituição e hoje. Evidentemente que um governo tendente a integrar a economia brasileira na ordem internacional deveria mexer nas normas constitucionais que tocam a ordem econômica. Óbvio, também, que os parâmetros da previdência social, diante dos graves problemas de seu financiamento, mereceram mudanças. Como o processo constituinte levou a uma Constituição marcadamente conjuntural, uma nova situação na conjuntura política ou econômica exige que se mexa no texto. ${ }^{23}$

Aquele desejo de colocar tudo no texto da Constituição, ao qual já fizemos referência, revelava uma desconfiança em relação às instituições e um certo medo da política. Foram nutridas esperanças de qualidades quase mágicas da Constituinte. Basta lembrar o samba de enredo que dizia "espero da Constituinte na minha mesa muito pão, uma poupança cheia de cruzados e um carnaval com muita paz no coração". ${ }^{24}$ Por outro lado, no processo constituinte não ficou caracterizada uma maioria homogênea, o que permitiu a inclusão de interesses eventualmente majoritários. ${ }^{25}$

No entanto, não são as decisões constituintes revelações de deuses. Não são ontologicamente superiores a outras decisões humanas. Muitas das decisões de uma Assembléia constituinte são tomadas em contextos de negociatas e trocas de favores entre grupos que colocam no texto consti-

\footnotetext{
23 "A imodéstia constituinte difícilmente fica impune e o poder constituinte evolutivo acaba por ser a sanção da imodéstia e da arrogância do poder constituinte, quando ele não é capaz de ousar acima da conjuntura da sua própria época" (MOREIRA, 2001, p. 274).

${ }^{24}$ Samba da Caprichosos de Pilares, do Rio de Janeiro, para o carnaval de 1987.

25 "O constituinte de 1987/1988, nesse sentido, teria cometido excessos, constitucionalizando temas que poderiam ter ficado para o legislador ordinário. O fato de a Constituinte não ter realizado seu trabalho a partir de um projeto predeterminado, mas a partir de vinte e quatro subcomissões, criou sérios problemas de sistematização. Essas subcomissões, além de trabalhar isoladamente umas das outras — o que gerou dificuldades em sintonizar todas as perspectivas num documento inicial — também atuaram, em muitos casos, de forma sobreposta. Somado a esse problema técnico, a Constituição foi o resultado de uma determinada conjuntura política em que nenhum dos grupos conseguiu estabelecer hegemonicamente seu projeto político. Assim, diversos dispositivos constitucionais resultam da força de maiorias meramente eventuais, aglutinadas especialmente para a inserção de um tópico no texto constitucional" (VIEIRA, Oscar Vilhena. A Constituição e sua Reserva de Justiça: um ensaio sobre os limites materiais ao poder de reforma. São Paulo: Malherios, 1999. p. 133).
} 
tucional seus interesses incompatíveis com qualquer idéia de interesse geral.

A decisão de tornar algo imodificável no texto da Constitucional deve ser extremamente amadurecida, pois se trata de congelar, enquanto durar a Constituição, a discussão política sobre aquele tema. O não modificável deveria ser somente aquilo fundamental para a própria existência da comunidade. ${ }^{26}$ Em especial, direitos fundamentais, cuja observância estaria acoplada ao próprio conceito de democracia.

A democracia, aqui, é vista não simplesmente como governo da maioria. Alguns elementos formam as condições para que seja aceitável a decisão da maioria. Majoritariamente, tais elementos decorrem da necessidade de garantir a autonomia dos agentes que formam a comunidade.

As citadas objeções não comprometem, ao nosso ver, a legitimidade da existência dos procedimentos mais difíceis para alterar a Constituição. Abalam, porém, a fundamentação de qualquer cláusula proibitiva de alteração. A incompatibilidade, portanto, não está entre rigidez e democracia, mas entre vedação de discussão e democracia. ${ }^{27}$

A proteção por procedimentos mais complexos reconhece a necessidade de que decisões fundamentais, ou seja, que incidem sobre matérias de especial relevância para a comunidade, não podem ficar sujeitar a um processo aberto infinito de discussão. A mudança freqüente de parâmetro para as atividades dos indivíduos, ditadas por maiorias eventuais, levaria à deslegitimação do próprio Estado.

A Constituição da República Federativa do Brasil entroniza um largo rol de dispositivos no espaço protegido, com a regra contida no $\S 4^{\circ}$ do art. 60. Diz que não será passível de deliberação emenda tendente a abolir a separação de poderes, o voto direto, secreto, universal e periódico, a forma federativa de Estado e os direitos e garantias fundamentais.

No entanto, não se trata de uma cláusula de imodificabilidade. A alteração é possível, desde que não identificada uma tendência à abolição daquelas decisões. Isso significa que alterações pontuais, que não desestruturem os esquemas traçados pelo Constituinte ou, até mesmo, que os reforce serão aceitas, mesmo que alterem artigos devotados às matérias ali definidas.

De 1988 aos nossos dias algumas alterações nesses campos foram levadas a cabo sem que tenha sido reconhecida uma ofensa à proibição de alteração. Veja-se, por exemplo, a mudança, na Emenda Constitucional

\footnotetext{
${ }^{26}$ LAPORTA, 2001, p. 474.
}

${ }^{27}$ LAPORTA, 2001, p. 482.

A \& C R. de Dir. Administrativo e Constitucional, Belo Horizonte, ano 6, n. 24, p. 163-174, abr./jun. 2006 
n. 32, da titularidade do poder de organizar e estruturar Ministérios e órgãos da Administração. Tal poder, até então, estava nas mãos do Congresso Nacional, tendo passado à decisão do Poder Executivo. Ora, apesar de incidir sobre a separação de poderes, já que altera limites na relação entre Legislativo e Executivo, não se pode falar que houve tendência à abolição da cláusula protegida.

\section{Referências}

ASENSI SABATER, José. Constitucionalismo y Derecho Constitucional: Materiales Para Una Introduccíon. Valência: Tirant lo Blanch, 1996.

BÖCKENFÖRDE, Ernest-Wolfgang. Estudios sobre el Estado de Derecho y la Democracia. Tradução de Rafael Serrano. Madri: Trotta, 2000.

CANOTILHO, J. J. Direito Constitucional e Teoria da Constituição. 2. ed. Coimbra: Almedina, 1998.

CANOTILHO, J. J. Gomes. Estado de Direito. Lisboa: Gradiva, 1999.

GARZÓN VELDÉS, Ernesto. Representación y Democracia. Doxa, Alicante, n. 6, p. 143161, 1989.

HELLER, Hermann. Teoria do Estado. Tradução de Lycurgo Gomes da Motta. São Paulo: Mestre Jou, 1968.

HOLMES, Stephen. Precommitment and the Paradox of Democracy. In: ELSTER, Jon; SLAGSTAD, Rune (Org.). Constitutionalism and Democracy. Cambridge: Cambridge, 1988.

JIMENEZ ASENSIO, Rafael. El Constitucionalismo. Madri: Marcial Pons, 2003.

KELSEN, Hans. Teoria Geral do Direito e do Estado. Tradução de Luís Carlos Borges. São Paulo: Martins Fontes, 1992.

LAPORTA, Francisco. El Ámbito de la Constitución. Doxa, Alicante, n. 24, p. 459-484, 2001.

LASSALE, Ferdinand. O que é uma Constituição Política. Tradução de Manoel Soares. São Paulo: Global, 1987.

MOREIRA, Vital. Constituição e Democracia na Experiência Portuguesa. In: MAUÉS, Antônio. Constituição e Democracia. São Paulo: Max Limonad, 2001.

ZAGREBELSKY, Gustavo. El Derecho Dúctil. Tradução de Marina Gascón. Madri: Trotta, 1999. Informação bibliográfica deste texto, conforme a NBR 6023:2002 da Associação Brasileira de Normas Técnicas (ABNT):

SANTOS, Gustavo Ferreira. Constituição e democracia: reflexões sobre permanência e mudança da decisão constitucional. A\&C Revista de Direito Administrativo e Constitucional, Belo Horizonte, ano 6, n. 24, p. 163-174, abr./jun. 2006.

A \& C R. de Dir. Administrativo e Constitucional, Belo Horizonte, ano 6, n. 24, p. 163-174, abr.jun. 2006 